\title{
HYDROXYL FUNCTIONALIZED GRAPHENE AS A SUPERIOR ANODE MATERIAL FOR ELECTROCHEMICAL OXIDATION OF METHYLENE BLUE
}

\author{
Yusbarina Yusbarina ${ }^{1,3}$, Roto Roto ${ }^{1, \bigotimes}$ and Kuwat Triyana ${ }^{2}$ \\ ${ }^{1}$ Department of Chemistry, Gadjah Mada University, Sekip Utara Yogyakarta, 55281, Indonesia \\ ${ }^{2}$ Department of Physics, Gadjah Mada University, Sekip Utara Yogyakarta, 55281, Indonesia \\ ${ }^{3}$ Department of Chemistry Education, State Islamic University of Sultan Syarif Kasim Riau, \\ Pekanbaru, 28293, Indonesia \\ \Corresponding Author: roto05@ugm.ac.id
}

\begin{abstract}
Graphene and its derivates are among the emerging materials to be studied extensively for many electrochemical applications. The work's objective is to learn the hydroxyl functionalized graphene-modified electrode in the electrochemical oxidation of methylene blue, which is known as a significant industrial dye. Hydroxyl functionalized graphene $(\mathrm{G}-\mathrm{OH})$ has been synthesized using graphite as a precursor by a combination of electrochemical exfoliation and sonication methods. Graphite was electrochemically exfoliated in $1,0 \mathrm{M} \mathrm{Li}_{2} \mathrm{SO}_{4}$ solution for $2 \mathrm{~h}$ to produce oxidized graphene flakes. The oxidized graphene flakes were sonicated in $75 \%$ acetone for $2 \mathrm{~h}$ to yield G-OH. The product crystal structure and elemental composition were checked with XRD and SEMEDX. The produced G-OH has an atomic content of $\mathrm{C} 77,98 \%$ and $\mathrm{O} 22,02 \%$. We also confirmed the product by UV-Vis, FTIR, and Raman spectrometries. The G-OH was deposited on the stainless-steel electrode (SS) and tested in the electrochemical oxidation of methylene blue (MB). The cyclic voltammogram of the bare SS electrode and $\mathrm{SS} / \mathrm{G}-\mathrm{OH}$ modified electrode gives oxidation current peak detected at $-0,61 \mathrm{~V}$ by $0,47 \mathrm{~mA}$ and $5,58 \mathrm{~mA}$, respectively. It suggested a high electrocatalytic ability of the SS/G-OH electrode for the electrochemical oxidation reaction. The electrochemical process by the electrode could degrade $>92 \%$ of the initial MB within 5 min and $>$ 99\% within 30 min. The GC data suggested that $\mathrm{MB}$ mainly degraded to $\mathrm{CO}_{2}$ and $\mathrm{H}_{2} \mathrm{O}$. This graphene-based electrode could be a potential for the electrochemical oxidation of many organic pollutants to yield environmentally friendly products.

Keywords: Hydroxyl Functionalized Graphene, Exfoliation, Sonication, Electrochemical Degradation, Methylene Blue
\end{abstract}

RASĀYAN J. Chem., Vol. 14, No.2, 2021

\section{INTRODUCTION}

Azo dyes are extensively used in textile and cosmetic industries, usually discharged majority during the dyeing process into the effluents. ${ }^{1}$ The toxic and carcinogenic properties of these wastewaters cause health problems in aquatic living. ${ }^{2}$ Azo dyes are non-biodegradable dyes, so that they must be treated before discharging into the environment. Electrochemical oxidation is an effective waste treatment method widely used to degrade dyes, ${ }^{3}$ such as methylene blue. Electrochemical oxidation's advantages are mild and straightforward operating conditions under ambient temperature and pressure and the potential to produce $\mathrm{CO}_{2}$ and $\mathrm{H}_{2} \mathrm{O}$ as final products. ${ }^{4}$

The efficiency of the electrochemical oxidation reaction depends highly on the nature of the electrode material and the operational conditions. ${ }^{5}$ Many electrodes have been used, such as boron-doped diamond, ${ }^{6}$ $\mathrm{IrO}_{2}-\mathrm{SnO}_{2}-\mathrm{Sb}_{2} \mathrm{O}_{5}{ }^{7}$ with a diverse target of dyes. The electrodes are so expensive that they are less applicable for wastewater treatment. ${ }^{8}$ In most electrochemical degradation trials, efficiency usually remains to be the main issue.

Carbon-based materials are suitable electrodes for wastewater treatment because of their high conductivity, availability, and non-toxicity. Based on previous studies, graphene-based materials can be applied as electrode material in the electrochemical oxidation process. ${ }^{9-11}$ Graphene is a 2D thin sheet of carbon network with $\mathrm{sp}^{2}$ hybridization. It has excellent mechanical strength, outstanding catalytic 
properties, and corrosion resistance. ${ }^{12}$ The functionalization of graphene with an oxygen-containing functional group presented high electrocatalytic performance for the degradation of dyes. ${ }^{13,14}$ The functionalization of graphene with hydroxyl functional group creates hydroxyl functionalized graphene (G-OH). G-OH contains a lot of hydroxyl groups on its structure that determine its reactivity in the electrochemical oxidation of the dyes. The production processes for G-OH are simple with two-step synthesis in a relatively short time at room temperature, with no need for complex equipment, and without the use of hazardous chemicals.

The objective of the work is to investigate the hydroxyl functionalized graphene-modified electrode in the electrochemical oxidation of methylene blue, one of the industrial azo-dyes. In this work, the synthesis of oxidized graphene was carried out by electrochemical exfoliation. The sonication process was applied to give G-OH. The SS/G-OH modified electrode was prepared by anodic electrodeposition. The modified G$\mathrm{OH}$ electrode was confirmed first by cyclic voltammetry before electrochemical oxidation of MB in the $\mathrm{NaCl}$ solution. The progress of the electrochemical oxidation reaction was monitored by UV-Vis spectrophotometry. The product of the electrolysis was analyzed using GC-MS.

\section{EXPERIMENTAL}

\section{Materials}

Graphite rod with $99.99 \%$ purity was acquired from Walfront, China. Lithium sulfate, acetone, sodium chloride, hydrochloric acid, and methylene blue (MB) were purchased from Merck, Germany.

\section{Instrumentation}

We used a Thermo Scientific UV-Vis spectrophotometer to record UV-Vis spectra and a Shimadzu Prestige 21 to acquire FTIR spectra. A Rigaku Miniflex600 XRD with $\mathrm{CuK} \alpha$ radiation was applied to obtain XRD patterns. A Hitachi Scanning Electron Microscope SU3500 was used to record SEM-EDX data. The Raman spectra were recorded by Horiba Scientific's Raman spectrometer equipped with LabSpec 6 software. An industrial DC power supply of Sanfix SP-305E was used to perform electrochemical exfoliation of graphene as well as electrochemical oxidation. The cyclic voltammetry was performed on an eDAQ Potentiostat controlled with Echem v2.1.0 software. The product of electrochemical degradation of MB was identified by using a Shimadzu QP-2010S GC-MS.

\section{Synthesis of G-OH}

The electrochemical exfoliation process was carried out in the electrochemical cell, which consists of both cathode and anode of graphite rods with a diameter of $10 \mathrm{~mm}$. The electrolyte was $1,0 \mathrm{M}$ lithium sulfate. Both electrodes were parallel arranged in such a way with a distance of $1 \mathrm{~cm}$. The electrodes were connected to an industrial DC power supply with an applied voltage of $8,0 \mathrm{~V}$ for $120 \mathrm{~min}$. The exfoliated product of electrolysis was filtered and washed with distilled water. $0,2 \mathrm{~g}$ of the solid was dispersed in $100 \mathrm{~mL}$ of $75 \%(\mathrm{v} / \mathrm{v})$ acetone solution and sonicated for $120 \mathrm{~min}$ to obtain G-OH dispersion. The hydroxyl functionalized graphene was dried at $80{ }^{\circ} \mathrm{C}$ for $2 \mathrm{~h}$ before further characterization with SEMEDX, XRD, UV-Vis, FTIR, and Raman spectrometries.

\section{Preparation of SS/G-OH electrode}

The preparation of the SS/G-OH electrode was carried out by using an anodic electrodeposition method using a DC power supply. The 316L stainless steel (SS) electrode with dimensions of 5,0-cmx3,0-cm was wet sand-papered with emery paper, degreased using detergent, and then sequentially sonicated in acetone, anhydrous ethanol, and double-distilled water. The bare electrode was immersed in the $2 \mathrm{~g} / \mathrm{L}$ G$\mathrm{OH}$ dispersion to deposit the $\mathrm{G}-\mathrm{OH}^{15}$ and supplied with a voltage of $30 \mathrm{~V}$ for 3 min with $316 \mathrm{~L}$ stainless steel as an anode and cathode. The cyclic voltammetry (CV) of the obtained SS/G-OH working electrode was recorded using eDAQ Potentiostat. Pt electrodes as cathodes and $\mathrm{Ag} / \mathrm{AgCl}$ electrodes as reference electrodes. The $\mathrm{CV}$ was measured in the supporting electrolyte of $0,1 \mathrm{M} \mathrm{NaCl}$.

\section{Electrochemical Oxidation of MB Using SS/G-OH Electrode}

Electrochemical oxidation of $20 \mathrm{mg} / \mathrm{L}$ MB with $0,05 \mathrm{M} \mathrm{NaCl}$ electrolyte solution was carried out in batch type electrolysis cell of $100 \mathrm{~mL}$ volume using an industrial DC power supply with the prepared SS/G-OH electrode as anode and SS cathode. The electrochemical oxidation study was carried out using the current 
RASĀYAN J. Chem.

Vol. 14 | No. 2 |1140-1147| April - June | 2021

density $20 \mathrm{~mA} / \mathrm{cm}^{2}$, the solution initial $\mathrm{pH} 3$, and various electrolysis times of 5,15, 30, and $60 \mathrm{~min}$. The electrolysis progress was monitored by using a UV-Vis spectrophotometer. The product of the electrolysis was analyzed using GC-MS.

\section{Synthesis of G-OH}

\section{RESULTS AND DISCUSSION}

The synthesis of G-OH was done according to the reactions (1). Synthesis of graphene and its derivates by the electrochemical exfoliation has advantages including ease to operate, operating at ambient temperature, and environmentally friendly. ${ }^{16}$ Factors affecting the thickness and oxygen content of graphene flakes are the type and concentration of electrolytes and the operational conditions of electrolysis. ${ }^{17}$ Since $1 \mathrm{M}$ lithium sulfate was used as an electrolyte, $\mathrm{SO}_{4}{ }^{2-}$ is attracted to the anode and intercalated into the inter-graphite layer, causing an increase in the distance between the layers. ${ }^{18}$ Besides sulfate ions, $\mathrm{OH}^{-}$produced from water oxidation also undergoes intercalation into the graphite layer. ${ }^{19}$ These intercalation processes cause exfoliation of the graphite layer into thinner layers of graphene flakes. During exfoliation, graphene could partially oxidize to yield oxidized graphene, as shown in reaction (1). Ultrasonication improves the exfoliation of graphite by providing additional energy to break the van der Waals bond. ${ }^{20}$ Ultrasonication provides the necessary activation energy for electronic transfer to form G$\mathrm{OH}^{21}$. Also, hydrogen atoms and hydroxyl radicals are generated by transient cavitation in aqueous solutions, which may react with solutes in the bulk of the solution. ${ }^{22,23}$ The hydroxyl radical causes oxidized graphene to be oxidized to yield more hydroxyl in the graphene structure.

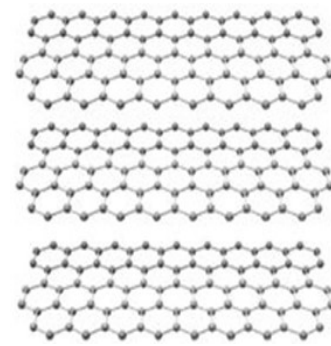

Graphite

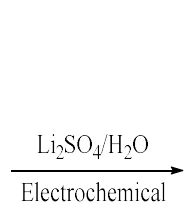

exfoliation

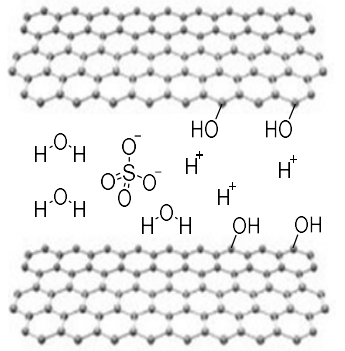

Oxidized graphene flakes

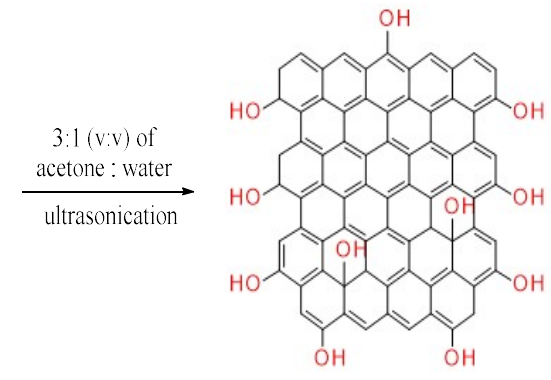

Hydroxyl functionalized graphene

Reaction-1: Synthesis of hydroxyl functionalized Graphene

\section{Characterization of G-OH}

The FTIR data is shown in Fig.-1. The strong peak at $3425 \mathrm{~cm}^{-1}$ is indicative of the O-H stretching vibration mode. The G-OH has a much stronger peak at $3425 \mathrm{~cm}^{-1}$ than that of oxidized graphene. The peak at $1620 \mathrm{~cm}^{-1}$ is indicative of the $\mathrm{O}-\mathrm{H}$ bending vibration mode. The $\mathrm{C}-\mathrm{O}$ vibration mode of $\mathrm{G}-\mathrm{OH}$ is viewed at a peak at $1126 \mathrm{~cm}^{-1}$. The peak at $1720 \mathrm{~cm}^{-1}$ is absent, meaning that there is no $\mathrm{C}=\mathrm{O}$ bond in the structure of $\mathrm{G}-\mathrm{OH}$. A peak near $2924 \mathrm{~cm}^{-1}$ is due to the presence of $\mathrm{C}_{\mathrm{sp} 3}-\mathrm{H}$ stretching vibration mode. All of the indicative FTIR peaks confirm the previous reports. ${ }^{24}$

Figure-2 shows the UV-Vis spectrum of G-OH. A single peak at $266 \mathrm{~nm}$ is observed. It could be assigned as a $\mathrm{C}=\mathrm{C}$ bond of the graphene hexagonal structure. It is believed to be due to the excitation of the $\mathrm{C}=\mathrm{C}$ framework of graphene..$^{25}$ The XRD pattern of G-OH shows a decrease in peak intensity at $26.7^{\circ}$. Typical (002) peak of graphene was observed at $2 \theta$ of $\sim 26^{\circ}$ (JCPDS Number 01.0646). ${ }^{26}$ Many small peaks could be due to the diffraction of graphite, which was not converted into graphene.

The $\mathrm{I}_{\mathrm{D}} \mathrm{I}_{\mathrm{G}}$ ratio obtained from the Raman spectrum is commonly used to evaluate the defect in graphene and other carbonaceous materials. ${ }^{20}$ The $\mathrm{I}_{\mathrm{D} / \mathrm{I}}$ of oxidized graphene flakes and $\mathrm{G}-\mathrm{OH}$ are 1,03 and 1,26 , respectively. The increase of the $\mathrm{I}_{\mathrm{D}} / \mathrm{I}_{\mathrm{G}}$ ratio in the G-OH (Fig.-4) suggests that the graphene flakes have been functionalized with hydroxyl groups. The hydroxyl groups present in the graphene edges cause an increase in the amount of carbon $\mathrm{sp}^{3}$, thereby increasing the degree of carbon defects. The same results were obtained in the report earlier. ${ }^{24}$

The SEM-EDX results show that multilayer graphene with a composition of $83,75 \% \mathrm{C}$ and $16,25 \% \mathrm{O}$ was formed in the electrochemical exfoliation step. The sonication process causes the addition of hydroxyl groups in graphene to form $\mathrm{G}-\mathrm{OH}$ with a chemical composition of $77,98 \% \mathrm{C}$ and $22,02 \% \mathrm{O}$. It 
RASĀYAN J. Chem.

Vol. 14 | No. 2 |1140-1147| April - June | 2021

gives a measured $\mathrm{O} / \mathrm{C}$ atomic ratio of 1:4. The reported work showed that graphene oxide has about $40 \%$ $\mathrm{C}_{\mathrm{sp} 3}$ bonding with a measured $\mathrm{O} / \mathrm{C}$ atomic ratio of $1: 5 .^{27}$

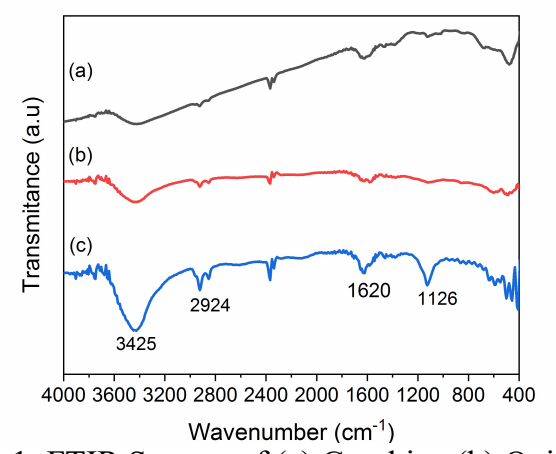

Fig.-1: FTIR Spectra of (a) Graphite, (b) Oxidized Graphene, and (c) G-OH.

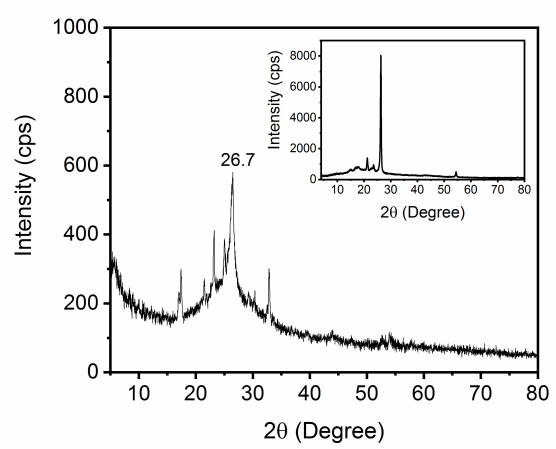

Fig.-3: XRD Pattern of G-OH, insert: XRD Pattern of Graphite

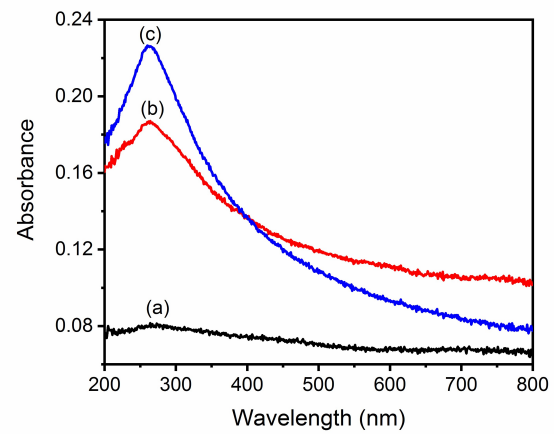

Fig.-2: UV-Vis Spectra (a) Graphite, (b) Oxidized Graphene, and (c) G-OH.

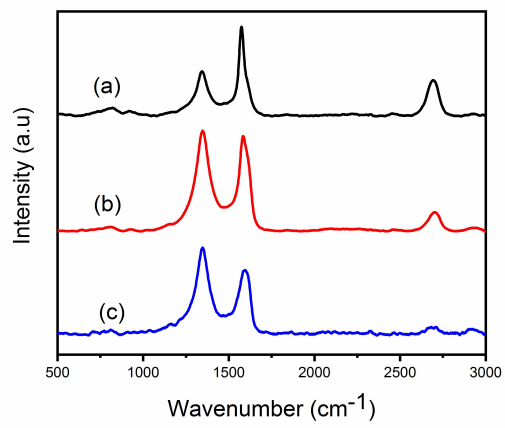

Fig.4: Raman Spectra of (a) Graphite, (b) Oxidized Graphene, and (c) G-OH

\section{Cyclic Voltammetry of G-OH}

Instead of using glassy carbon to limit the interference of another carbonaceous surface, we use a stainless-steel electrode. The cyclic voltammogram of the SS/G-OH electrode was recorded to understand the redox process of the modified electrode. Figure- 6 shows the produced CV. The G-OH was deposited on the SS electrode by the electrochemical reaction. The bare SS electrode shows redox peak currents centered at $-0,61 \mathrm{~V}$ with the cathodic and anodic peak currents of about $0,47 \mathrm{~mA}$. It could be attributed to the redox of proton/hydrogen. ${ }^{28}$

The SS/oxidized graphene (SS/G) and SS/G-OH modified electrode give oxidation current peak detected at $-0,61 \mathrm{~V}$ by $3,94 \mathrm{~mA}$ and $5,58 \mathrm{~mA}$, respectively. The oxidation of $\mathrm{Cl}^{-}$to $\mathrm{Cl}_{2}$ and the ease of reducing $\mathrm{Cl}_{2}$ to $\mathrm{Cl}^{-}$occurs at the $\mathrm{SS} / \mathrm{G}-\mathrm{OH}$ electrodes during the oxidation and reduction scan, respectively. The performance of the electrode could be due to the successful functionalization of the graphene to hydroxyl groups. According to the previous works, the reactions (2), (3), (4), and (5) could occur. ${ }^{29}$
$\mathrm{G}-\mathrm{OH} \rightarrow \mathrm{G}-\mathrm{O}^{\bullet}+\mathrm{H}^{+}+\mathrm{e}^{-}$
$\mathrm{G}-\mathrm{O}^{\bullet}+\mathrm{OH}^{-} \rightarrow \mathrm{G}^{-} \mathrm{O}^{-}+{ }^{\bullet} \mathrm{OH}$

$$
\begin{aligned}
& \mathrm{G-O} \bullet+\mathrm{Cl}^{-} \rightarrow{\mathrm{G}-\mathrm{O}^{-}+\mathrm{Cl} \bullet}_{\mathrm{Cl} \bullet+\mathrm{Cl}^{-} \rightarrow \mathrm{Cl}_{2}+\mathrm{e}-}
\end{aligned}
$$

Modification of the electrodes and the electrocatalytic reaction of species in the solution have been extensively studied. ${ }^{30-33}$ The same results occur for the $\mathrm{CV}$ of the $\mathrm{Ti} / \mathrm{TiO}_{2}-\mathrm{NiO}_{2}$ electrode in the blank electrolyte. Ti electrode surface that does not contain redox-active species produces a smaller peak current than that of the $\mathrm{Ti} / \mathrm{TiO}_{2}-\mathrm{NiO}_{2}$ electrode. ${ }^{34}$

Indirect electrolysis of organic compounds relies on the oxidation of pollutants by oxidizing species produced in situ on the electrode surface. ${ }^{5}$ One of the potent oxidizing agents is the hydroxyl radical $\left({ }^{\circ} \mathrm{OH}\right)$. It is very reactive with organic compounds. ${ }^{35}$ Hydroxyl functionalized graphene $(\mathrm{G}-\mathrm{OH})$ contains a 
RASĀYAN J. Chem.

lot of hydroxyl groups on its structure that determine its reactivity in the electrochemical degradation of the organic compounds. The use of $\mathrm{G}-\mathrm{OH}$ as an electrode coating material could provide excessive hydroxyl radicals $\left({ }^{\circ} \mathrm{OH}\right)$, which will act as a strong oxidizing agent according to the reactions (2) and (3). The ${ }^{\circ} \mathrm{OH}$ radical could react readily with species available in the solution. Also, if $\mathrm{NaCl}$ solution is used as a supporting electrolyte, the $\mathrm{G}-\mathrm{OH}$ could further oxidize $\mathrm{Cl}^{-}$to $\mathrm{Cl}_{2}$ which is also known as a potent oxidizing agent according to the reactions (4) and (5). It will increase the electrocatalytic performance of the $\mathrm{G}-\mathrm{OH}$ as an electrode modifier in the electrochemical degradation of organic compounds.
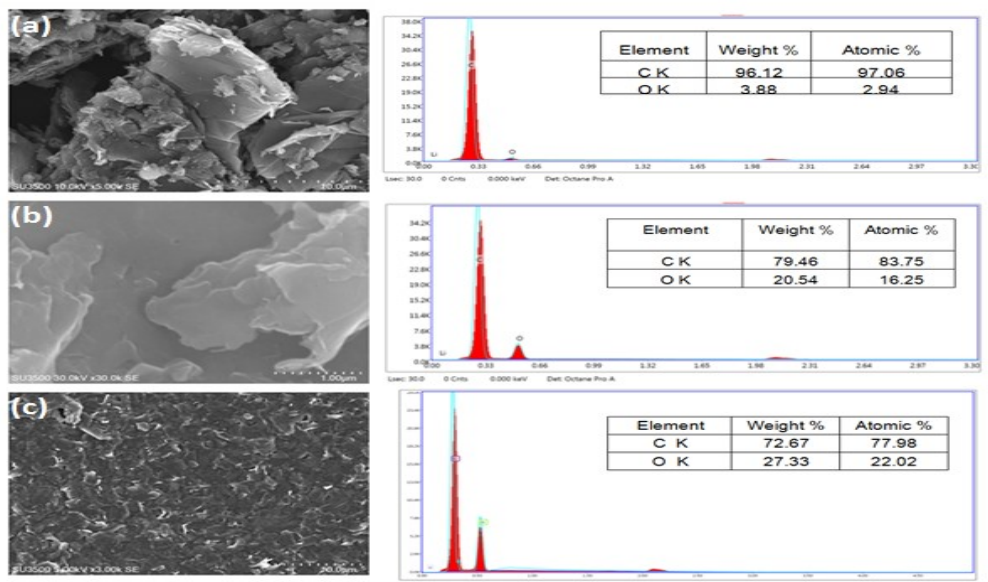

Fig.-5: SEM and EDX Results of (a) Graphite, (b) Oxidized Graphene, and (c) G-OH.
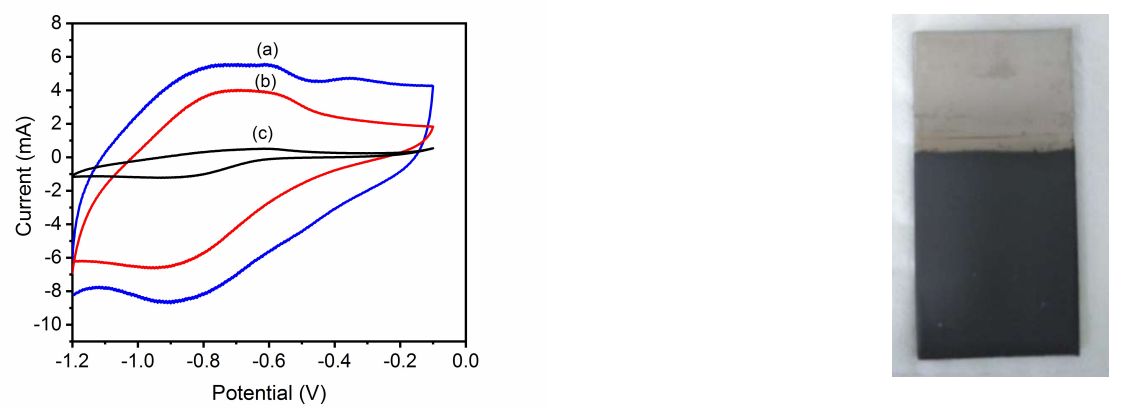

Fig.-6: Cyclic Voltammogram of (a) G-OH modified electrode, (b) Oxidized Graphene-modified Electrode, and (c) Blank Electrode in $0,10 \mathrm{M} \mathrm{NaCl}$ with a Scan Rate of $50 \mathrm{mV} / \mathrm{s}$. The right is the modified electrode.

\section{Electrochemical Oxidation of MB}

In this work, we used MB as a model for the azo dye, which has an aromatic group with the formula of $\mathrm{C}_{16} \mathrm{H}_{18} \mathrm{~N}_{3} \mathrm{SCl}$ and is one of the cationic dyes with strong adsorption power. It has three absorbance peaks in the UV-Vis region at 246, 292, and $664 \mathrm{~nm}$, respectively. The decrease in the absorbance in the UVVis region indicates degradation. A decrease absorbance intensity at the peak of $664 \mathrm{~nm}$ mainly suggests the deterioration of the MB structure. In comparison, the absorbance intensity decrease in the UV region at 292 and $246 \mathrm{~nm}$ indicates that the benzene ring structure and the conjugation system of the phenothiazine species have been decomposed. ${ }^{36}$

Based on Fig.-7, after $5 \mathrm{~min}$ of electrolysis, the peak at $664 \mathrm{~nm}$ decreased by $92 \%$, at $292 \mathrm{~nm}$ by $87 \%$, and at $246 \mathrm{~nm}$ by $74 \%$. The peak at $664 \mathrm{~nm}$ reduced entirely after $30 \mathrm{~min}$ of electrolysis. Since the peak at $246 \mathrm{~nm}$ also disappears, the benzene ring seems to break down.

As indicated by the UV-Vis spectrum, the degradation product of MB was supported by the GC-MS data. Figure-8(a) show the gas chromatograms of the product after $5 \mathrm{~min}$ of electrolysis. The mass spectrometry results show that the main intermediate products of electrochemical oxidation of MB are organic acids. It confirms the proposed pathway of degradation methylene reported before. ${ }^{37}$ 
RASĀYAN J. Chem.

As suggested by GC-MS results in Fig.-8, based on the $\mathrm{m} / \mathrm{z}$ value of the main products of peak \#6 and peak \#9 detected at the retention time of 34,4 min and 37,9 min are decanoic and 11-octadecenoic acids, respectively. According to the $\mathrm{m} / \mathrm{z}$ value, a smaller peak than the previous ones at a retention time of 45,8 min (peak \#12) is believed to be benzene-1,2-dicarboxylic or phthalic acid. A single benzene ring's appearance suggests that $\mathrm{MB}$ was degraded to a single ring structure before degrading further to give small molecules, mainly $\mathrm{CO}_{2}$ and $\mathrm{H}_{2} \mathrm{O}$.

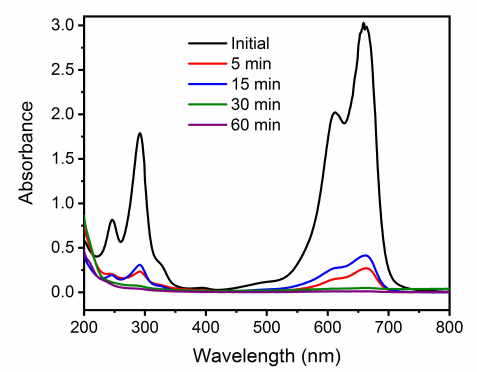

Fig.-7: UV-Vis Spectra of 20 ppm MB with a variation of electrolysis times, the initial current density was set at 20 $\mathrm{mA} / \mathrm{cm}^{2}$, solution initial $\mathrm{pH} 3$, the distance between the electrodes of $1.0 \mathrm{~cm}$

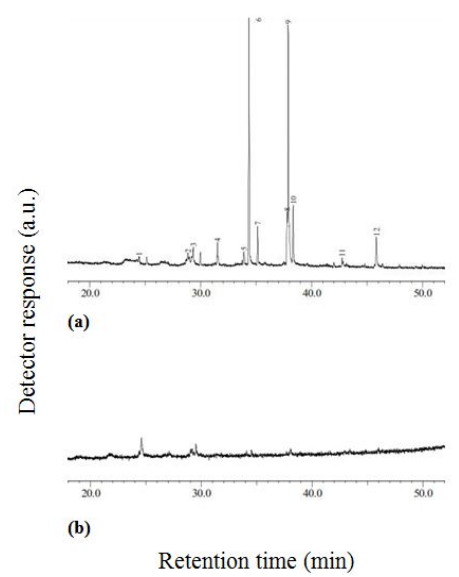

Fig.-8: Gas Chromatograms of the MB electrolysis product using SS/G-OH modified electrode, (a) after electrolysis for 5 $\mathrm{min}$ and (b) for $30 \mathrm{~min}$, at a current density of $20 \mathrm{~mA} / \mathrm{cm}^{2}$.

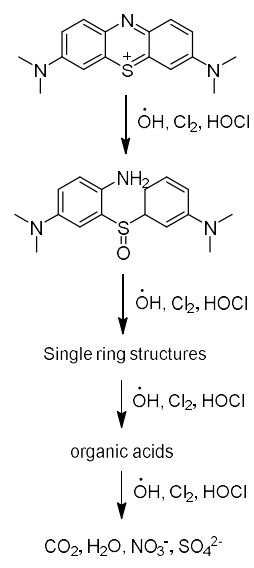

Fig.-9: Proposed Reaction Mechanism of MB degradation by electrochemical degradation by using SS/G-OH electrode.

Figure-8(b) shows the gas chromatogram of the electrolysis product for $30 \mathrm{~min}$. The mass spectra were not shown since there is no appreciable gas chromatogram was observed. The gas chromatograph peak is small, which indicates that the intermediate product has been degraded to $\mathrm{CO}_{2}, \mathrm{H}_{2} \mathrm{O}$, and small organic species. However, it might contain water-soluble species. The proposed reaction pathway is indicated in Fig. -9 .

The appearance of intermediate products indicates that the electrochemical oxidation of MB using SS/G$\mathrm{OH}$ electrodes occurs in two steps. First, the $\mathrm{MB}$ molecules react with the surface $\cdot \mathrm{OH}$ radicals and soluble oxidizing agents, presumably $\mathrm{Cl}_{2}$ and $\mathrm{HOCl}$, to yield smaller linear molecules. Second, these small molecules further degraded to produce $\mathrm{CO}_{2}$ and $\mathrm{H}_{2} \mathrm{O}$.

Consistent with the UV-Vis and GC data of the electrolysis product, it suggests that the SS/G-OH electrode catalyzes MB's electrochemical degradation reaction to produce environmentally friendly compounds that are $\mathrm{CO}_{2}$ and $\mathrm{H}_{2} \mathrm{O}$. Thus, the SS/G-OH electrode may potentially find application in the electrochemical degradation of other pollutants.

\section{CONCLUSION}

We applied a combination of electrochemical exfoliation and sonication to produce multilayer hydroxyl functionalized graphene. The product had an elemental composition of $77,98 \% \mathrm{C}$ and $22,02 \% \mathrm{O}$. The 
RASĀYAN J. Chem.

Vol. 14 | No. 2 |1140-1147| April - June | 2021

electrochemical oxidation of $\mathrm{MB}$ using SS/G-OH electrode in $\mathrm{NaCl}$ electrolyte showed that the MB concentration decreased by $>99 \%$ after 30 min of electrolysis. The analysis results by GC-MS suggest that $\mathrm{MB}$ degraded to $\mathrm{CO}_{2}, \mathrm{H}_{2} \mathrm{O}$, and other water-soluble species. It indicates that hydroxyl functionalized graphene can be extended as anode material for different industrial azo dyes' electrochemical oxidation.

\section{ACKNOWLEDGMENT}

We thank the Ministry of Religion of the Republic of Indonesia for the 5000 Doctoral Scholarships Program, the Ministry of Research, Technology, and Higher Education of the Republic of Indonesia for Penelitian Disertasi Doktor (PDD) grant (grant number 3070/UNI.DITLIT/DIT-LIT/PT/2020), and the Ministry of Education and Culture of the Republic of Indonesia for Riset Kolabarosi Indonesia (RKI) grant (grant number 812/UN1/DITLIT/DIT-LIT/PT/2020).

\section{REFERENCES}

1. A. Singh, S. Kumar, V. Panghal, S. S. Arya, and S. Kumar, Rasayan Journal of Chemistry, 12(4), 1956(2019), DOI:10.31788/RJC.2019.1245401

2. S. M. A. G. Ulson de Souza, E. Forgiarini, and A. A. Ulson de Souza, Journal of Hazardous Materials, 147, 1073(2007), DOI:10.1016/j.jhazmat.2007.06.003

3. E. Isarain-Chávez, Electrochimica Acta, 244, 199(2017), DOI:10.1016/j.electacta.2017.05.101

4. S. Garcia-segura, J. D. Ocon, and M. Nan, Process Safety and Environmental Protection, 113, 48(2018), DOI:10.1016/j.psep.2017.09.014

5. J. Radjenovic and D. L. Sedlak, Environmental Science and Technology, 49, 11292(2015), DOI:10.1021/acs.est.5b02414

6. W. R. P. Barros, J. R. Steter, M. R. V. Lanza, and A. J. Motheo, Electrochimica Acta, 143, 180(2014), DOI: 10.1016/j.electacta.2014.07.141

7. R. Chaiyont, C. Badoe, C.P de León, J.L. Nava, F.J. Recio, I. Sirés, P. Herrasti, and Walsh, Chemical Engineering and Technology. 36(1), 123(2013), DOI:10.1002/ceat.201200231

8. A. Mukimin, K. Wijaya, and A. Kuncaka, Indonesian Journal of Chemistry, 10(3), 285(2010), DOI:10.22146/ijc.21431

9. M. Safarpour and A. Khataee, 2019, Graphene-Based Materials for Water Purification, In Micro and Nano Technologies, Nanoscale Materials in Water Purification, Elsevier Inc., New York, pp. 383430, DOI:10.1016/B978-0-12-813926-4.00021-5

10. J. Li, Q. Guan, J. Hong, and C. Chang, Journal of Nanoscience and Nanotechnology, 19(11), 7308(2019), DOI:10.1166/jnn.2019.16656

11. R. B. Kohakade, E. Senthil Kumar, R. W. Gaikwad, S. Raghu, and R. A. Kalaivani, Rasayan Journal of Chemistry, 10(4), 1151(2017), DOI:10.7324/RJC.2017.1041881

12. S. Stankovich, D.A. Dikin, G.H.B. Dommett, K.M. Kohlhaas, E.J. Zimney, E.A. Stach, R.D. Piner, S.B.T. Nguyen, and R.S. Ruoff, Nature, 442, 282(2006), DOI:10.1038/nature04969

13. N. P. Shetti, S. J. Malode, R. S. Malladi, S. L. Nargund, S. S. Shukla, and T. M. Aminabhavi, Microchemical Journal, 146, 387(2019), DOI:10.1016/j.microc.2019.01.033

14. H. Saroyan, G. Z. Kyzas, and E. A. Deliyanni, Processes, 7(1), 40 (2019), DOI:10.3390/pr7010040

15. L. Chen, Y. Tang, K. Wang, C. Liu, and S. Luo, Electrochemistry Communication, 13(2), 133(2011), DOI:10.1016/j.elecom.2010.11.033

16. P. Divya, A. Prithiba, and R. Rajalakshmi, Rasayan Journal of Chemistry, 12(1), 214(2019), DOI:10.31788/RJC.2019.1215039

17. J. I. Paredes and J. M. Munuera, Journal of Material Chemistry A, 5, 7228(2017), DOI: $10.1039 / \mathrm{c} 7 \mathrm{ta} 01711 \mathrm{a}$

18. K. Parvez, Z. Wu, R. Li, X. Liu, R. Graf, and X. Feng, Journal of The American Chemical Society, 136, 6083(2014), DOI:10.1021/ja5017156

19. K. Parvez, R. Li, S.R. Puniredd, Y. Hernandez, F. Hinkel, S. Wang, X. Feng, and K. Mullen, ACS Nano, 7(4), 3598(2013), DOI:10.1021/nn400576v

20. W.S. Chow, Y., Suda, A.A. Thant, M. Mariatti, and W.S.Chow, Applied Surface Science, 469, 951(2018), DOI: 10.1016/j.apsusc.2018.11.029 
RASĀYAN J. Chem.

Vol. 14 | No. 2 |1140-1147| April - June | 2021

21. D. Majumdar and S. Pal, Journal of Fundamentals Renewable Energy and Applications, 6(3), (2016), DOI: 10.4172/20904541.1000209

22. P. Riesz, D. Berdahi, and C. L. Christman, Environmental Health Perspective, 64, 233(1985).

23. M. Kohno, T. Mokudai, T. Ozawa, and Y. Niwano, Journal of Clinical Biochemistry Nutrition, 49(2), 96(2011), DOI:10.3164/jcbn.10

24. L. Yan, M. Lin, C. Zheng, Z. Chen, S. Zhang, X. Zhao, A. Wu, Y. Wang, L. Dai, J. Qu, M. Guo, and Y. Liu, Journal of Materials Chemistry, 22, 8367(2012), DOI:10.1039/c2jm30961k

25. S. Uran, A. Alhani, and C. Silva, AIP Advances. 7, 35323 (2017), DOI:10.1063/1.4979607

26. M. L. Chen, C. Y. Park, J. G. Choi, and W. C. Oh, Journal of the Korean Ceramic Society, 48(2), 147(2011), DOI: 10.4191/KCERS.2011.48.2.147

27. K.A. Mkhoyan, A.W. Contryman, J. Silcox, D.A. Stewart, G.Eda, C. Mattevi, S. Miller, and M. Chhowalla, Nano Letters, 9(3), 1058(2009), DOI:10.1021/n18034256

28. F. Termemil, S. Soualmia, and M. R. Benloucif, Journal of Materials and Environmental Science, 8(10), 3777(2017).

29. A. Mukimin, Ph.D. Thesis, Department of Chemistry, Gadjah Mada University, Yogyakarta, Indonesia, (2013).

30. R. Roto and G. Villemure, Journal of Electroanalytical Chemistry, 527(1-2), 123(2002), DOI: $10.1016 / \mathrm{S} 0022-0728(02) 00834-3$

31. R. Roto, A. Yamagishi, and G. Villemure, Journal of Electroanalytical Chemistry, 572(1), 101(2004), DOI: 10.1016/j.jelechem.2004.06.005

32. R. Roto and G. Villemure, Journal of Electroanalytical Chemistry, 588(1), 140(2006), DOI:10.1016/j.jelechem.2005.12.014

33. R. Roto and G. Villemure, Journal of Electroanalytical Chemistry, 601(1-2), 112(2007), DOI:10.1016/j.jelechem.2006.10.041

34. G. Fadillah, A. Saleh, and S. Wahyuningsih, Journal of Molecular Liquids 289(2019), DOI:10.1016/j.molliq.2019.111108

35. F. C. Moreira, R. A. R. Boaventura, E. Brillas, and V. J. P. Vilar, Applied Catalysis B: Environmental, 202, 217(2017), DOI:10.1016/j.apcatb.2016.08.037 0926-3373/C

36. X. Yu, L. Huang, Y. Wei, J. Zhang, and Z. Zhao, Materials Research Bulletin, 64, 410(2015), DOI:10.1016/j.materresbull.2015.01.009

37. Q. Wang, S. Tian, and P. Ning, Industrial \& Engineering Chemistry Research, 53, 643(2014), DOI:10.1021/ie403402q

[RJC-6180/2020] 